\title{
UNA ANUNCIACIÓN DEL MAESTRO DE PEREA RECUPERADA PARA ESPAÑA
}

Uno de los Maestros de transición entre el siglo XV y XVI con personalidad más destacada entre los segidores valencianos de Jacomat y Rexach es el Maestro de Perea.

Tormo fue el que le dio el nombe basándose en el encargo que Pedro de Perea en 1491 hizo de un retablo para la capilla de los Tres Reyes en la iglesia de Santo Domingo de Valencia y que actualmente se encuentra en el museo de Bellas Artes de dicha ciudad ${ }^{1}$. El retablo debió de hacerse más tarde después de su muerte, pues fue su mujer Violante de Santa Pau la que se encarga de la ejecución definitiva. Tormo considera a Perea como cabeza de una escuela poco exquisita pero «vistosa y popular». Creo que es excesiva su afirmación de denominarle «prerrafae_ lista».

Post considera al Maestro de Perea fundador de un movimiento, continuador del arte de Rexach y Jacomart, que fluctúa entre el Gótico y el Renacimiento y del que derivan otros maestros como el de los Artés, Játiva y Martínez, a los que hay que adjudicar obras que se habían venido atribuyendo al Maestro de Perea ${ }^{2}$.

Gudiol estableció con más generosidad los caracteres estilísticos del Maestro de Perea, considerando su estilo como la refundición de influjos anteriores y contemporáneos pero no sabiendo el pintor escapar de ciertas rigideces para un período tan avanzado. En sus composiciones, a pesar de la brillantez externa y al empaque que logra en ellas, persiste la monotonía ${ }^{3}$.

Hoy estudiamos una Anunciación, en colección privada madrileña $(140 \times 96 \mathrm{~cm})$, que creemos de su mano, aunque Gaya Nuño, en la Pintura española fuera de España, la atribuyó al Maestro de Játiva, pero advirtiendo que era «preciosa y riquísima versión, sin duda la más importante obra del artista». En efecto, y por eso se la atribuimos al Maestro Perea, los modelos del Maestro de Játiva carecen del empaque, monumentalidad y belleza de aquel (Fig. 3). La escena se desarrolla en un interior, con un pupitre angular de madera sobre el que se halla el ramo de azucenas y el libro en el que lee la Virgen. Sobre el suelo de decorada losería se arrodillan el ángel y la Virgen y el cerrado espacio se abre al fondo por un ventanal con paisaje en la parte baja en el que destaca la noria típica de la zona levantina ${ }^{4} \mathrm{y}$, en la parte superior, sobre fondo de oro, la Paloma del Espíritu Santo. Las figuras ya no fluctúan ni se mueven como en el gótico, sino que aparecen asentadas, los cuerpos y los dulces y redondeados rostros muestran cierto naturalismo y, entre los personajes monumentales, hay relación por la posición de los mismos. Todavía hay evocaciones hispano-flamencas en el interés por lo accesorio y lo táctil como las calidades de brocados diademas, etc. La técnica es temple sobre tabla con oro estofado y repujado.

Los bellos modelos del ángel y de la Virgen, las diademas de perlas que adornan sus cabezas, los plegados, brocados y decoración de los bordes de los mantos, la losería del pavimento e incluso el tarro de azucenas - torpe en su ejecución pero de azucenas espigadas- la ponen en relación no sólo con el retablo de los Tres Reyes (Figs. 4-7), sino con los modelos de la Mado-

\footnotetext{
1 Tormo, E.: «Comentario a la filiación histórica», Archivo Español de Arte, 1932, p. 33; «El barón de San Petrillo: "Filiación histórica de los Primitivos valencianos"», Archivo Español de Arte, 1932, p. 15, no cita al Maestro de Perea. Ver también Catálogo de la Exposición del siglo XV valenciano, Madrid, Palacio de Exposiciones del Retiro, octubre-diciembre, 1973, p. 65 .

${ }^{2}$ Post, R. Ch.: A History of Spanish Painting, Cambridge, Mass Harwrd University Press, 1935, vol. VI (1. ${ }^{\text {a }}$ parte) p. 268.

${ }^{3}$ Gudiol, J.: «Pintura Gótica», en Ars Hispaniae, vol. IX, p. 256, Madrid, 1935.

${ }^{4}$ No muestra todavía el desarrollo de la tabla de la Visitación del Prado que consideramos de etapa más avanzada.
} 


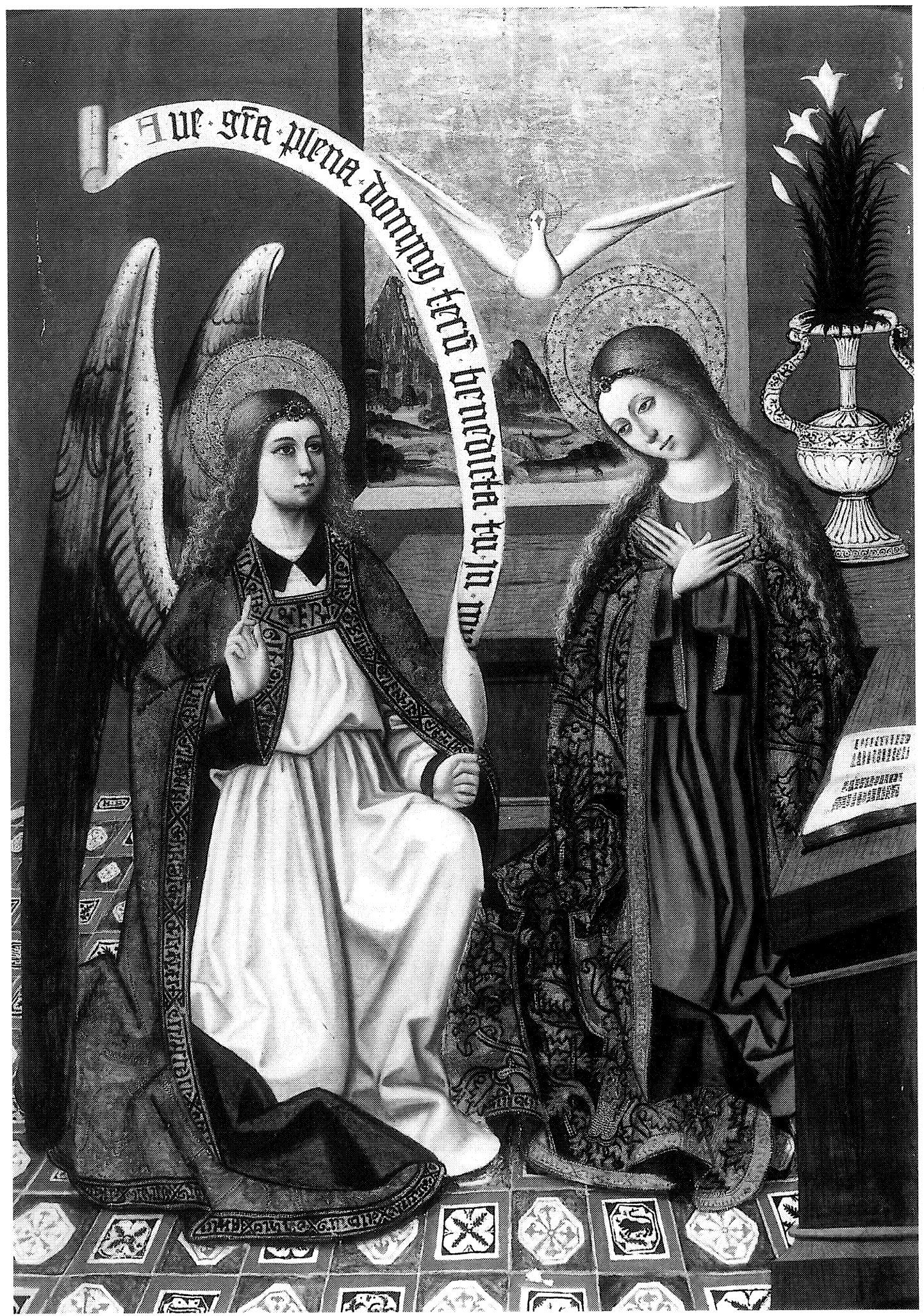

Fig. 3. Maestro de Perea. Anunciación. Madrid. Colección privada. 


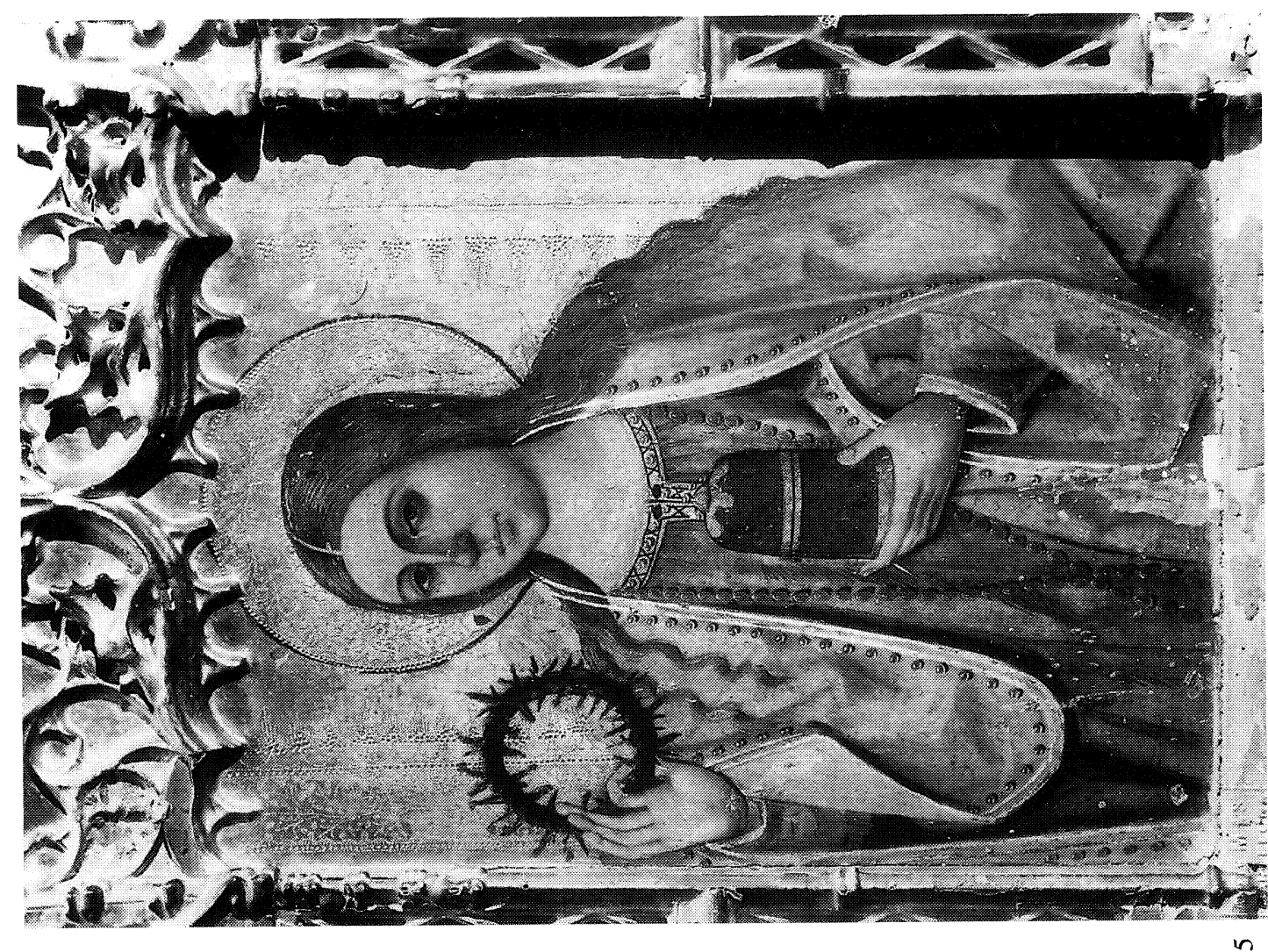

$\forall$

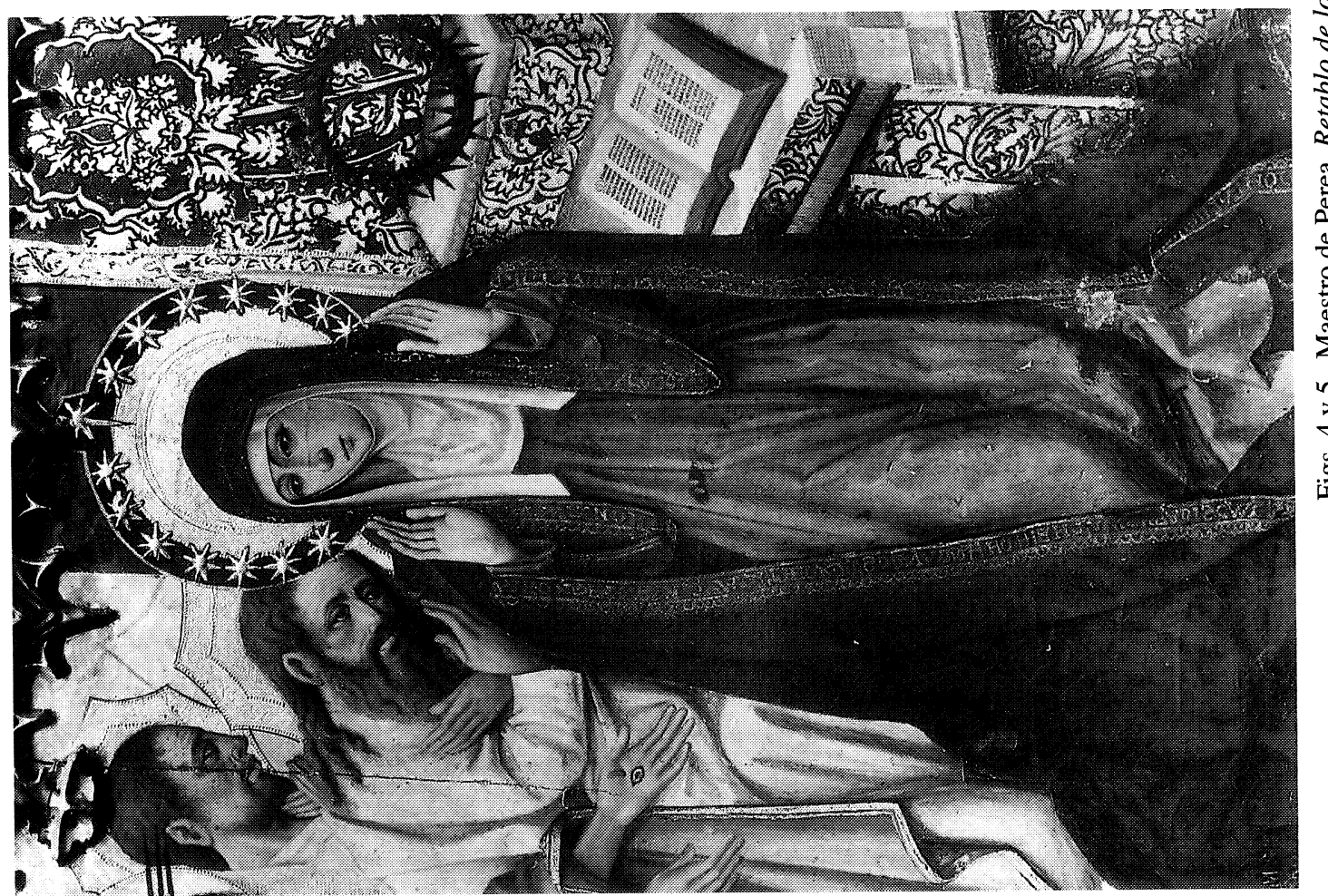



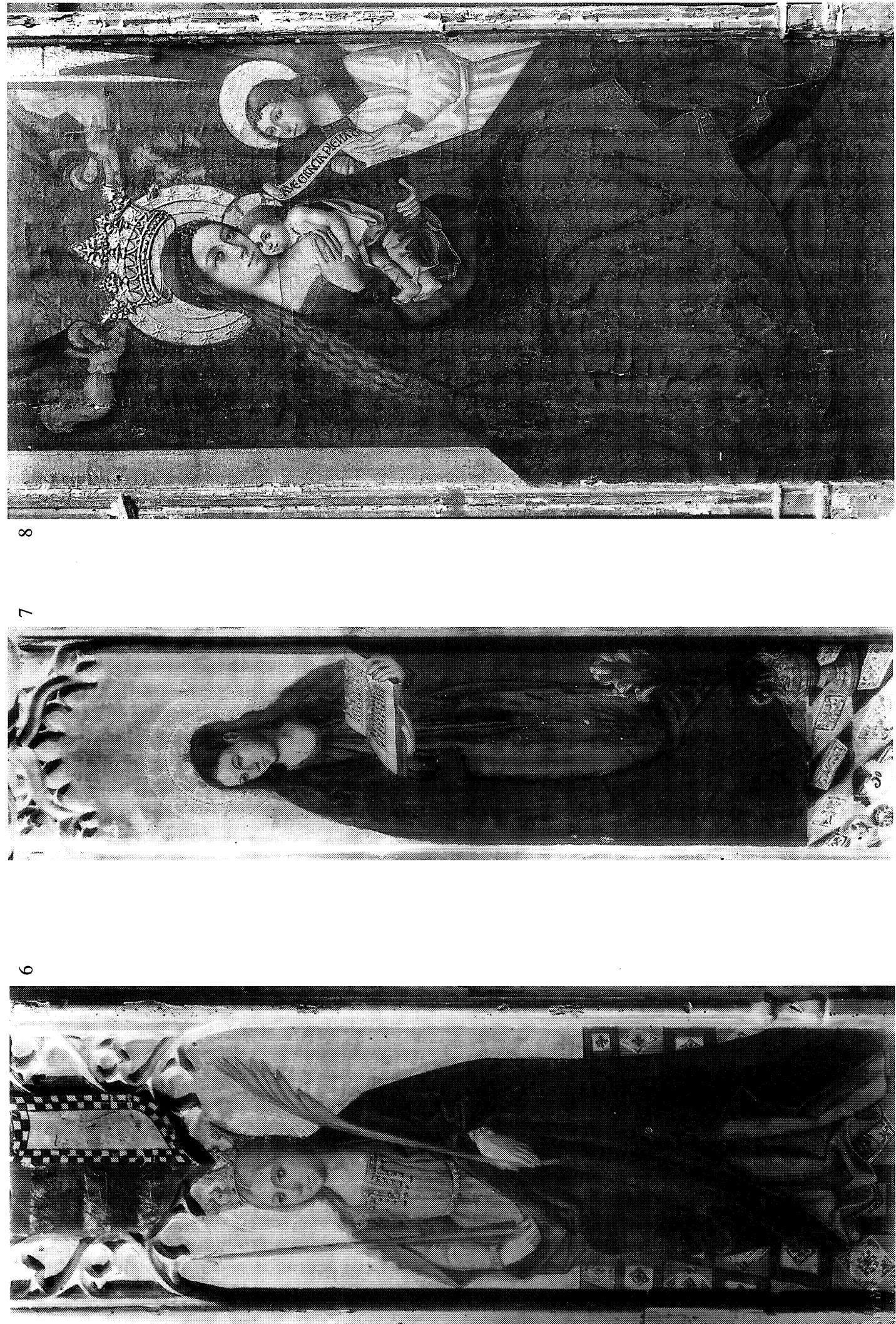
na con Ángeles, del retablo de Santa Ana de la Colegiata de Játiva y con la Madona del Museo de Artes Decorativas de París (Fig. 8). Por la foto que reproduce Gaya Nuño de ella ${ }^{5}$, podemos observar que la tabla actualmente se halla restaurada, y en ciertas zonas excesivamente, aunque no afecta a partes importantes de la obra.

ISABEL MATEO GÓMEZ

Dpto. H. ${ }^{a}$ del Arte del CSIC

\section{EL RETABLO MAYOR DE LA CATEDRAL DE ASTORGA. UN CONCURSO ESCULTORICO EN LA ESPAÑA DEL RENACIMIENTO}

Durante el obispado de Don Diego Sarmiento de Sotomayor en la ciudad de Astorga, en la provincia de León, se llevó a cabo, en el año 1558, el concurso para la ejecución del retablo mayor de la catedral de Astorga. Tres propuestas de escultores fueron presentadas al obispo y al cabildo del templo astorgano: el 26 de marzo del 1558 la de los escultores Juan Picardo y su yerno Pedro Andrés «estantes en Medina del Campo»; el 22 de mayo, la del grupo de escultores palentinos, Miguel Alvarez, Juan Ortiz y Luis Ortiz y el 8 de agosto la del escultor y pintor baezano Gaspar Becerra. En 1908, los tres proyectos fueron mencionados por primera vez, por Pedro Rodríguez López, pero sólo la del vencedor Becerra fue publicado ${ }^{1}$. Descuido o desinterés, que llama la atención si pensamos que Picardo y Alvarez fueron considerados por sus contemporáneos los «mejores oficiales que al presente ay en estos Reynos en el oficio e arte de ymaginería e de los bultos» en España ${ }^{2}$. La comparación de estos dos proyectos inéditos, que logré identificar en el Archivo Diocesano de Astorga, con el de Becerra, analizado en el 1969 por Juan José Martín González, completa el conocimiento sobre uno de los concursos escultóricos más importantes de la España del Renacimiento.

Juan Picardo y Pedro Andrés prometían concluir el trabajo en 5 años, por un total de 2.500 ducados ${ }^{3}$, mientras que Miguel Alvarez, Juan Ortiz y Luis Ortiz se obligaban a terminar el retablo mayor en tres años, por 300 ducados más que los anteriores ${ }^{4}$. Sin embargo, el 24 de mayo, después de haber visto la traza presentada por Picardo y Andrés y haber leído la propuesta de éstos, los palentinos decidieron rebajar la demanda inicial a 2.300 ducados, o sea a 200 ducados menos que Picardo y Andrés. Lo curioso de esta enmienda es que los palentinos estaban no sólo dispuestos a abandonar su propio proyecto, sino que se ofrecían, por esta suma de dinero, realizar el retablo mayor siguiendo las instrucciones de los otros dos escultores: «manuel álvarez e luis ortiz e juan ortiz, vezinos de la çiudad de palençia, escultores, dixeron [...], que harán el dicho rretablo conforme a la dicha muestra, hecha e dada por los dichos juan picardo e pedro an-

\footnotetext{
${ }^{5}$ Gaya, Nuño: La Pintura española fuera de España, Madrid, 1958, lám. 47, cat. n. ${ }^{\circ}$ 1.511, entonces en la Arcade Gallery de Lóndres y hoy felizmente recuperada.

${ }^{1}$ Rodríguez López, P.: Episcopologio asturicense, vol. III, Astorga, 1908, pp. 41, 172-179 y Rodríguez Díez, M.: Historia de la muy Noble, Leal y Benemérita Ciudad de Astorga (1909), Astorga, 1981, pp. 802-806.

${ }^{2}$ Martí y Monsó, J.: Estudios histórico-artísticos, relativos principalmente a Valladolid, Valladolid, 1898-1901, p. 178

3 «Postura del rretablo dela y[gles]ia cathedral», 26 de marzo 1558, 3 fols. Leg.: Íñigo de Miranda-1558, Archivo Diocesano de Astorga (A.D.A.).

4 «Postura del rretablo dela yglesia cathedral de astorga q[ue] hizieron los de palençia», 22 de mayo de 1558, 6 fols. Leg.: Íñigo de Miranda-1558 (sin catalogar), A.D.A.
} 